\title{
$\mathbb{A}$ Economics Bulletin
}

\section{Volume 37, Issue 1}

\section{The short-run price elasticity of demand for energy in the US.}

\author{
Youngsoo Kim \\ Korea Atomic Energy Research Institute
}

Younoh Kim

Sam Houston State University
Vlad Radoias

Sam Houston State University

\begin{abstract}
We propose using cost shifters as valid instruments for the estimation of short-run price elasticity of demand for residential electricity. We argue that most of the previous studies do not address the endogeneity of price in the demand equation and hence suffer from simultaneity bias. Furthermore, we argue that using lagged prices or consumption as instruments clearly violates the exclusion restriction and overstates the magnitude of the short-run elasticity of demand. We propose using the price of coal and natural gas as instruments, since they are two of the most important inputs in the production of electricity in the U.S. We are able to estimate much smaller magnitudes of price elasticity, which implies that in the short run consumers are much less responsive to changes in prices than previously believed. Policies based on previous (higher) estimates are likely to take longer time to be effective, since these estimates are confounding short-run and long-run consumer responses to price changes.
\end{abstract}

Citation: Youngsoo Kim and Younoh Kim and Vlad Radoias, (2017) "The short-run price elasticity of demand for energy in the US.", Economics Bulletin, Volume 37, Issue 1, pages 606-613

Contact: Youngsoo Kim- yskim84@kaeri.re.kr, Younoh Kim- younoh@shsu.edu, Vlad Radoias - radoias@shsu.edu.

Submitted: December 21, 2016. Published: March 29, 2017. 


\section{Introduction}

The demand for energy has increased dramatically with the economic and technological development of the last decades. Given the growing global concern on climate change, carbon emissions, and the fact that most of our energy is produced using non-renewable resources, policy-makers everywhere have tried to come up with solutions to increase energy efficiency and decrease overall energy use.

Naturally, for any such policy design one needs to understand the causes that affect the demand for energy. Basic economic theory tells us that the two most important factors that could affect the energy consumption are the own price of energy and the price of any available substitute. There have been many policies implemented around the globe such as taxes on fossil fuels, ecological taxes, mandatory energy efficiency measures in the construction and renovation of residential buildings, and even subsidies to promote energy efficiency and the use of renewable and clean energy as a substitute. However, often times these policies did not have the desired result. For instance, the American Recovery and Reinvestment Act of 2009 allocated $\$ 27.2$ billion toward energy efficiency projects, but often times consumers have been observed to pass up these opportunities (Alberini et al. 2011).

The effectiveness of any such policy, does not only depend on establishing a theoretical link between energy consumption and its determinants, but also depends on establishing and correctly estimating the magnitude of this link. In particular, any policy targeting the price of energy (either directly through taxes, or indirectly through subsidies on more desirable substitutes) relies on the correct estimation of the price elasticity of demand for energy. There has been a flurry of literature on estimating this price elasticity, generally using aggregate national or state level data and trying to fit a demand equation using panel data models. Generally, the conclusion is that the demand for energy is price-inelastic. However, the estimates range dramatically, depending on the data and methodology used and also on the country being studied. For instance, Ziramba (2008) estimates a short-run price elasticity of demand of only 0.02 using data from South Africa, while Tanishita (2009) estimates a short-run elasticity between 0.5 and 0.9 using data from Japan. For studies using U.S. data, the estimates in the short run generally range between 0.2 and 0.35 (Alberini and Filippini 2011).

In terms of methodologies used, many of the previous studies fail to recognize the simultaneity of price and consumption. Estimating any demand function cannot be properly done by simply regressing quantities on prices and controlling for other factors. Prices are endogenous in this case and have to be properly instrumented for. Among the few studies that tried to use instrumental variables techniques are Alberini and Filippini (2011) and Okajima and Okajima (2013). However, both of these papers use lagged electricity prices, respectively lagged prices and lagged consumption as instruments, which we believe does not satisfy the exclusion restriction.

In this paper, we propose using cost shifters as instruments. We use prices of coal and prices of natural gas as instruments. While gas has been used in most of the previous literature as a substitute for electricity, we argue that, at least in the short run, residential consumers cannot easily substitute between gas and electricity. Therefore, gas affects the electricity market mainly as an input for electricity production, just as coal does. An EIA report from 2014 shows that half of power plant capacity additions in 2013 came from natural 
gas.

We are able to estimate short-run price elasticities of demand much lower in magnitude than previously thought. We are also able to estimate a benchmark case where current price is instrumented with past prices and clearly show the upward bias that these estimates have. Furthermore, we use a novel approach of constructing instruments based on heteroskedasticity proposed by Lewbel (2012) that allows us to test the two different subsets of instruments for validity. The method clearly shows lagged prices to be endogenous, and validates our use of coal and gas prices as valid external instruments.

\section{Data and Methodology}

We collect most of the data from the U.S. Energy Information Administration (EIA) publicly available sources. The EIA is an organization belonging to the U.S. Department of Energy and a principal agency of the U.S. Federal Statistical System responsible for analyzing and disseminating energy related data. Although one of the the EIA's main goals is promoting sound policymaking, it functions as an independent and impartial agency. All of its products are independent of approval by policy-makers.

We collect EIA data, covering 46 U.S. states over a time period between 2002-2009. The states of California, Oregon, Washington, Alaska, and Hawaii have been excluded based on missing data considerations. We collect information of residential energy consumption (in million kilowatt-hours), residential energy prices (in cents per kilowatt-hour), and coal and natural gas prices (in cents per million BTU). The fuel information is available on a monthly basis, while residential electricity consumption and prices are on an annual basis. For matching purposes, annual average fuel prices were computed. There is some missing information in fuel prices at some smaller states level, and we used the prices of fuels in the neighboring region to account for this missing data. ${ }^{1}$

In addition to the energy related data collected from EIA sources, we also collected data on personal income from the Bureau of Economic Analysis (BEA) and data on consumer price index (CPI) from the Bureau of Labor Statistics (BLS). All prices and income variables were then recalculated and expressed in real terms, in 1982 dollars. Another important correlate of energy consumption is weather fluctuations, so we collected data on heating and cooling degree days from the National Oceanic and Atmospheric Administration (NOAA).

We are interested in estimating the price elasticity of demand for energy consumption. Previous studies found varying estimates, depending on the method used, which, we argue, suffer from severe biases caused by the inherent endogeneity pervasive in quantity-price type relationships. Although some (see Shin 1985) have argued that at the aggregate level prices are exogenous from consumption, no definitive proof exists and major concerns still remain. This is especially so in the energy industry where certain pricing schemes exist that specifically determine the price of electricity as a function of quantity consumed. ${ }^{2}$ There is also the issue of measurement error that has been raised by Alberini and Filippini (2011) that also can lead to biased estimates. Some efforts have been made to properly instrument

\footnotetext{
${ }^{1}$ For instance, coal prices in CT are missing in March 2003. We replaced this missing data with coal prices in New England before averaging out the annual prices.

${ }^{2}$ For instance, it is common to find electricity price incentives during periods of high demand.
} 
for prices, however we believe the methods and instruments used were not appropriate.

Studies such as Alberini and Filippini (2011) or Okajima and Okajima (2013) use lagged electricity prices or even lagged electricity consumption as instruments for current prices and estimate dynamic panel models in a Blundell-Bond GMM (Blundell and Bond, 1998), respectively Arellano-Bond FD-GMM setting (Arellano and Bond, 1991). While this identification approach can work really well in a variety of other settings, we argue that using previous prices or consumption levels as instruments for current electricity prices clearly violates the exclusion restriction and are therefore invalid instruments. It is extremely surprising to us that studies that clearly focus on short- and long-run elasticities for energy fail to realize that the lagged prices they use as instruments clearly affect current consumptions not only through current prices, but also directly, and therefore violate the exclusion restriction and create upward bias on the short-run elasticity estimates.

Consider for instance residential consumers who faced high prices for energy in the past, and were able to transition to more efficient energy-consuming appliances in the meantime. Their current consumption will not only respond to current prices, but will be lower (everything else equal and regardless of current prices) because of this transition to energy efficient appliances, which was a direct response to the previous prices. This is, after all, the reason for having higher elasticities of demand for energy in the long-run than in the short-run. The level of current consumption is the result of not only current prices, but also past prices. By using past prices as instruments and incorrectly excluding them from the second step of the estimation, these direct effects are artificially compounded with the indirect effects that past prices have on consumption through current prices and thus create an upward bias in the elasticity estimates.

Another common misspecification that we would argue against, is the use of gas prices as determinants of electricity consumption. The theoretical intuition behind including gas prices as a regressor is that gas is a substitute for electricity and therefore the price of gas will affect the demand for electricity. While this might sound plausible, we argue that most residential consumers cannot easily substitute between electricity and gas, at least in the short run. In fact, most household never substitute between gas and electricity, not even in the long run, as this would imply significant investments that are very costly. It is very rare that households switch an electric stove or heating system for a gas one or vice-versa from gas to electric. It is also virtually unheard of for a household to possess both electrical and gas systems that they could use alternatively and switch back and forth, in response to relative short-run price fluctuations. If anything, it is more likely that gas prices are actually supply shifters if energy is produced in natural gas power plants, or if energy producers adjust their prices in response to gas prices fluctuations. We therefore argue that instead of using gas prices as control variables for energy consumption, gas prices should be used as instruments, together with other potential cost-shifters such as coal prices. Our approach is inspired by structural models of demand estimation often used in the empirical industrial organization literature that frequently use cost-shifters as instruments to correctly identify the price effect on consumption.

Another frequent misconception in using instrumental variables (IV) models, is the interpretation of Sargan-Hansen J statistics for over-identifying restrictions. Alberini and Filippini (2011) claim their use of past prices as instruments is valid based on this J-statistic. However, it is worth noting that the J statistic can successfully rule out invalid instruments, 
but it cannot validate good instruments with certainty. To be more precise, the J statistic cannot test the exogeneity of instruments. It can test a subset of instruments against another subset, under the strong assumption that at least some instruments are indeed valid and the model is in fact identified, but when all instruments are endogenous, they may pass the overidentification test in spite of being in fact endogenous. Table 5 from Okajima and Okajima (2013) incidentally presents such a case and at the same time raises question marks about the validity of their own estimates. When they include one period lagged prices and two period lagged consumption as instruments, they find the J statistic to invalidate these instruments, however when augmenting these invalid instruments by adding a third instrument (the three period lagged consumption) the J statistic jointly validates all the instruments. Surely if the lagged price and two period lagged consumptions are not exogenous (as proven by their first specification), they should not be used at all as instruments in their second specification.

We argue against the use of lagged variables as instruments, on reasons that have to do with short-run and long-run responsiveness of consumers that were explained earlier. We use current coal and gas prices as instruments in our main specification and also adopt a novel approach proposed by Lewbel (2012) of constructing instruments based on heteroskedasticity. These heteroskedasticity-based instruments are valid by construction and can hence be correctly used as a reference point in Sargan tests of overidentification.

We will hence estimate the short-run elasticity of demand $\beta$, from the following equation:

$$
\log E C_{s t}=\alpha_{s}+\beta \log E P_{s t}+\gamma X_{s t}+\varepsilon_{s t}
$$

where $E C_{s t}$ is energy consumption in state $s$ at time $t, \alpha_{s}$ is the state fixed effect, $E P_{s t}$ are energy prices in state $s$ at time $t, X_{s t}$ is a vector containing other correlates (log of per capita income, heating and cooling degree days) for state $s$ at time $t$, and $\varepsilon_{s t}$ is the error term. As explained earlier, we do not believe that prices are exogenous, so we instrument $\log E P_{s t}$ with $\log C P_{s t}(\log$ of coal prices in state $s$ at time $t)$ and $\log G P_{s t}(\log$ of gas prices in state $s$ at time $t$ ).

A possible cause of concern, especially when using gas prices as instruments for electricity prices, is that the exclusion restriction is violated. That is, if gas and electricity are easily substitutable, the price of gas might affect electricity consumption both through the supply channel but also directly through the demand channel. If that is the case, gas prices should be used as a regressor, and not as an instrument for electricity prices. We argue that this is the long-run reality, when consumers have time to adjust their appliances in response to market dynamics to either electric appliances or gas appliances. In the short-run however, we believe this substitution is virtually impossible and hence gas prices should be used as instruments when computing short-run elasticities of demand for energy. Testing these over-identifying restrictions confirms this hypothesis.

As a robustness check, we also employ the method described in Lewbel (2012), which is a method of identifying parameters in regressions with endogenous or mis-measured regressors, when no external instruments are available. This methodology has been found to be reliable by previous research (see Giambona and Schwienbacker 2007, Emran and Hou 2008, Sabia 2007, or Rashad and Markowitz 2007) and is extremely useful not only to achieve identification in absence of traditional instruments, but also to augment regressions with traditional instruments and test different sub-sets of instruments for validity. The statistical testing 
of the over-identifying restrictions is liable to be erroneous because it relies on at least one instrument to be truly valid. By using Lewbel instruments, which are valid by construction, we can lend more credibility to these statistical tests. We use this method to test not only our proposed instruments, but also previously used instruments such as lagged prices, and contrast between the two.

\section{Results}

Table I presents the results of our estimations. In column 1, for benchmark purposes, we estimated the model using one-, two-, and three-period lagged prices as instruments. In column 2, we present the results of our main specification where gas and coal prices are instead used as instruments. Columns 3 and 4 present the same two cases, after augmenting with the Lewbel (2012) heteroskedasticity-based instruments. All specifications control for state fixed effects (not shown in the table for space considerations) and are estimated using the two-step general method of moments (GMM) with robust standard errors.

Table I: Regression Results

Dependent Variable: Log Energy Consumption

\begin{tabular}{ccccc}
\hline \hline Variables & $\begin{array}{c}\text { IV(1) } \\
\text { (lagged prices) }\end{array}$ & $\begin{array}{c}\text { IV(2) } \\
\text { (coal \& gas prices) }\end{array}$ & $\begin{array}{c}\text { IV(1)+Lewbel } \\
\text { (lagged prices) }\end{array}$ & $\begin{array}{c}\text { IV(2)+Lewbel } \\
\text { (coal \& gas prices) }\end{array}$ \\
\hline \hline Log Electricity Price & $-0.20664^{* * *}$ & $-0.08701^{* *}$ & $-0.15401^{* * *}$ & $-0.12845^{* * *}$ \\
& $(0.02501)$ & $(0.04271)$ & $(0.11469)$ & $(0.01132)$ \\
Log Income per Capita & $0.33116^{* * *}$ & $0.31280^{* * *}$ & $0.31857^{* * *}$ & $0.29412^{* * *}$ \\
& $(0.03513)$ & $(0.03667)$ & $(0.02881)$ & $(0.02899)$ \\
Heating Degree Days & $0.00004^{* * *}$ & $0.00004^{* * *}$ & $0.00004^{* * *}$ & $0.00004^{* * *}$ \\
& $\left(3.56 e^{-06}\right)$ & $\left(3.36 e^{-06}\right)$ & $\left(2.48 e^{-06}\right)$ & $\left(2.50 e^{-06}\right)$ \\
Cooling Degree Days & $0.00011^{* * *}$ & $0.00013^{* * *}$ & $0.00011^{* * *}$ & $0.00012^{* * *}$ \\
& $\left(8.28 e^{-06}\right)$ & $\left(9.76 e^{-06}\right)$ & $\left(5.15 e^{-06}\right)$ & $\left(5.17 e^{-06}\right)$ \\
Constant & $-8.72154^{* * *}$ & $-8.70681^{* * *}$ & $-8.64107^{* * *}$ & $-8.44207^{* * *}$ \\
& $(0.34788)$ & $(0.38128)$ & $(0.28223)$ & $(0.28452)$ \\
\hline \hline Sample Size & 230 & 230 & 230 & 230 \\
F-stat on Excluded IVs & 48.794 & 16.070 & 11.752 & 13.858 \\
Hansen J-stat & 11.926 & 1.504 & 70.764 & 58.013 \\
(p-value) & $(0.0026)$ & $(0.2201)$ & $(0.0282)$ & $(0.1771)$ \\
C-statistic & - & - & 16.336 & 2.594 \\
(p-value) & - & - & $(0.0010)$ & $(0.2734)$ \\
\hline \hline
\end{tabular}

robust standard errors in parentheses

*-significant at $10 \%$ level **-significant at $5 \%$ level ***-significant at $1 \%$ level

All of the estimated coefficients are highly significant and have the predicted sign. However the estimated coefficients in columns 1 and 3 present price elasticities of demand with an obvious upward bias (in their absolute values). As previously explained, when past prices are used as instruments and incorrectly excluded from the second regression stage, the estimated short-run elasticity of demand is higher than the actual one. That is because the 
direct effect of past prices is confounded with the indirect effect of past prices through current prices. When we use cost shifters as instruments, the absolute values of the magnitudes of estimated elasticities drop from 0.21 to 0.09 (when only external instruments are used) and from 0.15 to 0.13 (when Lewbel instruments are included as well). Even without our proposed instruments, just by simply including Lewbel instruments alongside past prices, significantly reduces the magnitude of the estimated elasticity by about $25 \%$ as compared with the case when only past prices are incorrectly used as instruments. The relative magnitude of this bias is extremely severe and we believe policies designed based on these severely biased estimates should be re-evaluated.

From a statistical perspective, all instruments satisfy the relevance assumption. The F-statistics on the excluded instruments from the first regression stage are all higher than 10 (the rule of thumb from Steiger and Stock 1997) and are hence correlated enough with the endogenous regressor not to create the problem of weak instruments. On the other hand however, when testing the exclusion restriction (the second major assumption that instrumental variables need to satisfy), we clearly see that using lagged electricity prices as instruments is not a good idea. First, the J-statistic rejects the use of lagged electricity prices in both column 1 and 3. This statistic tests the over-identifying restrictions for the entire set of instruments. The null hypothesis in this case is that all exclusion restrictions are valid. The null is clearly rejected in both specifications containing lagged electricity prices as instruments, but cannot be rejected in the two specifications containing coal and gas prices as instruments. Furthermore, using a C-statistic, we can actually test the validity of the external instruments using the Lewbel instruments as reference, since they are valid by construction. Again, comparing columns 3 and 4, we reject the validity of lagged electricity prices, but cannot reject the validity of coal and gas prices as instruments. This is a very important additional step, that can bring further piece of mind regarding instrument validity. As we previously mentioned, it is entirely possible that the J-statistic will falsely validate certain instruments is all of them are in fact not exogenous. Adding Lewbel instruments creates a benchmark that is exogenous by construction, which we can use to test different subsets of suspect instruments against.

We believe the precision of our estimates could be improved in future research by adding more cost shifters as external instruments and possibly using different cost shifters for different geographical areas that produce their energy using different resources. Especially in the case of the United States, there is enough variation across different states in terms of the main energy source to where these differences could create a weak IV problem at some state levels. The bias of the IV estimates is smaller than the bias of the OLS estimates only if the instruments are not weak. Although our instruments are not weak at the aggregate level, it is entirely possible that at some state levels they are actually not well correlated with electricity prices, for instance if certain states do not use coal or gas for energy production and instead produce energy from other sources that do not correlate well in terms of prices with gas or coal. Unfortunately, our existing data-set does not allow us to make current improvements in this regard. 


\section{Conclusions}

In this paper, we proposed a new instrumental variables method of correctly estimating the price elasticity of demand for electricity. We claim that any price-quantity relationship inherently suffers from endogeneity and therefore, prices should be correctly instrumented for. We also claim and prove that the use of past prices and past consumption levels as instruments is not appropriate and, if used, will result in biased estimates. We also provide an intuitive explanation of the direct correlation between past prices and current consumption that clearly shows lagged prices violate the exclusion restriction.

Using correct instruments, we have estimated the short-run price elasticity of demand for residential electricity to be significantly smaller than previously believed. We estimated the absolute values of elasticity of 0.09 and 0.13 respectively, depending on method. Both of these estimates are much smaller than the estimates using lagged electricity prices as instruments. These estimates are also much smaller than previous estimates found in the literature, which range from 0.20 to 0.35 in studies using U.S. data. Since our data-set only contains relatively recent information, it is entirely possible that using larger data-sets spanning further back in time will yield even lower estimated elasticities since the availability of substitutes increases with the overall technology level.

Correctly estimating the price elasticity of demand for energy is extremely important for policy making, and so is correctly distinguishing between short- and long-run elasticities. We believe that when past prices are used as instruments, because of the violation of the exclusion restriction, the short- and long-run elasticities are confounded and mis-estimated. Therefore, any policies based on such estimates risk from being sub-optimal.

We therefore believe that more replications and careful analyses of these markets are needed and research on the topic should not stop here. We strongly suggest future researchers to pay closer attention to the choice of instruments. Our results support cost shifters as potentially good instruments and we encourage further investigations using other cost shifters when data is available. Of particular interest would be studies that more carefully isolate geographically the main source of energy production and use technologically specific cost shifters applicable to that geographical location. For instance prices of coal and gas can be used for locations that generate their energy mainly from fossil fuels, prices or availability of nuclear material can be used for locations with nuclear energy production, and even completely exogenous natural factors such as precipitations or average annual wind speed and sunshine can be used for locations with a large proportion of energy produced from renewable resources. 


\section{References}

Alberini, A. and M. Filippini (2011) "Response of Residential Electricity Demand to Price: The Effect of Measurement Error" Energy Economics 33, 889-895.

Alberini, A., Gans, W., and D. Velez-Lopez (2011) "Residential Consumption of Gas and Electricity in the U.S.: The Role of Prices and Income" Energy Economics 33, 870-881.

Arellano, M. and S. Bond (1991) "Some Tests of Specification for Panel Data: Monte Carlo Evidence and an Application of Employment Equations" Review of Economic Studies 58, 277-297.

Blundell, R. and S. Bond (1998) "Initial Conditions and Moment Restrictions in Dynamic Panel Data Models" Journal of Econometrics 87,115-143.

Emran, M. and Z. Hou (2008) "Access to Markets and Household Consumption: Evidence from Rural China", unpublished manuscript, George Washington University.

Giambona, E. and A. Schwienbacher (2007) "Debt Capacity of Tangible Assets: What is Collateralizable in the Debt Market?", unpublished manuscript, University of Amsterdam.

Lewbel, A. (2012) "Using Heteroskedasticity to Identify and Estimate Mismeasured and Endogenous Regressor Models" Journal of Business and Economic Statistics, 30, 67-80.

Okajima, S. and H. Okajima (2013) "Estimation of Japanese Price Elasticities of Residential Electricity" Energy Economics 40, 433-440.

Rashad, I. and S. Markowitz (2007) "Incentives in Obesity and Health Insurance", NBER Working Paper No. W13113.

Sabia, J. (2007) "The Effect of Body Weight on Adolescent Academic Performance" Southern Economic Journal 73, 871-900.

Staiger, D. and J. Stock (1997) "Instrumental Variables Regression with Weak Instruments" Econometrica 65(3), 557-586.

Tanishita, M. (2009) "Estimation of Regional Price Elasticities of Household's Electricity Demand" Journal of the Japan Society of Energy and Resources 30, 1-7.

Ziramba, E. (2008) "The Demand for Residential Electricity in South Africa" Energy Policy 36, 3460-3466. 